\title{
TILÁPIAS (Actinopterygii: Cichlidae) COMERCIALIZADAS EM FEIRA DE SANTANA (BAHIA) COMO BIOINDICADORES DE POLUIÇÃO AMBIENTAL EM RIOS DA BACIA DO PARAGUAÇU
}

\author{
GEÍSA GOMES PEREIRA MOTA* \\ SUZI DEALMEIDA VASCONCELOS BARBONI** \\ MARCEL CARVALHO DE JESUS $* * *$
}

\begin{abstract}
Espécies de tilápias comercializadas no Centro de Abastecimento da cidade de Feira de Santana, Bahia (CAFS), foram utilizadas no presente trabalho para avaliar a condição dos rios da Bacia do Paraguaçu. Foram realizados testes de micronúcleo pisceo, sendo que sete coletas foram efetuadas nos meses de maio a agosto de 2008 e 22 espécimes de tilápias foram adquiridas. Três modelos de protocolos diferenciados foram utilizados. No primeiro modelo, as três etapas foram realizadas no mesmo dia, secagem do esfregaço, fixação com Metanol $100 \%$ e coloração com Giemsa 10\%. No segundo, somente a secagem foi efetuada no dia da coleta, sendo as demais etapas realizadas 24 horas depois. No terceiro e último, apenas a coloração foi realizada no dia subsequente. Do total de 20.000 células foram encontrados 119 micronúcleos, indicando a ação de genotóxicos nas células dos peixes. Seu consumo em larga escala pode estabelecer cadeia de contaminação por genotóxicos da população de Feira de Santana. Sugere-se a realização de estudos adicionais para identificação do agente e da cadeia de contaminação para que sejam implementadas medidas sanitárias para o restabelecimento das condições de saúde e qualidade de vida da população afetada.
\end{abstract}

PALAVRAS-CHAVE: BACIA DO PARAGUAÇU; BIOINDICADORES; TILÁPIAS; MICRONÚCLEOS.

* Bióloga Bacharel em Biologia Sanitária, Especialista em Zoologia e Gestão Ambiental, Laboratório de Microbiologia Aplicada, Ambiental e Saúde Coletiva (LAMASP), Universidade Estadual de Feira de Santana (UEFS), Feira de Santana, BA (e-mail: geisamota@yahoo.com.br).

** Bióloga, Doutora em Saúde Pública, Professora Assistente, UEFS, Coordenadora do LAMASP, Feira de Santana, BA (e-mail: suziavbarboni@gmail.com).

*** Bacharelando em Ciências Biológicas, LAMASP, Feira de Santana, BA (e-mail: marcelcarvalho_bio@yahoo.com.br). 


\section{INTRODUÇÃO}

A preocupação mundial diante das ameaças da poluição e do uso insustentável dos recursos traduz sua importância. A água, recurso reconhecidamente limitado, passa a ter grande valor econômico (SOARES, 2004).

$\mathrm{Na}$ Bahia, os recursos hídricos da Bacia do Paraguaçu estão vulneráveis em decorrência do lançamento de resíduos das atividades desenvolvidas em suas bacias hidrográficas. Salienta-se o uso de fertilizantes químicos, agrotóxicos, esgotos domésticos, disposição de lixo doméstico a céu aberto, exploração mineral e desmatamentos (BAHIA, 1995; 2001).

Para MEGER e TREVISIAN (2007), o bom gerenciamento dos recursos hídricos passa pela verificação da situação da qualidade e quantidade da água, com as condições ecológicas em que ela se encontra. Como a biota aquática está constantemente exposta a grande número de substâncias tóxicas lançadas no ambiente (ARIAS et al., 2007), a sua saúde reflete a qualidade e a sustentabilidade do ecossistema aquático (RAMSDORF, 2007).

Conforme ARIAS et al. (2008), bioindicadores são organismos ou comunidades que respondem à poluição ambiental, alterando suas funções vitais ou acumulando toxinas. Assim, podem fornecer informações necessárias para a análise de risco ecológico e estudos de impacto ambiental. Atuam como fatores bióticos no reconhecimento das condições de determinado ecossistema por conseguirem realizar a detecção precoce dos efeitos reais que possam estar ocorrendo aos seres vivos em virtude da exposição aos poluentes ambientais (ARIAS et al., 2007; ARIAS et al., 2008).

Dentre os muitos tipos de organismos utilizados como bioindicadores para avaliar possíveis efeitos de riscos naturais ou de origem antropogênica (MEDINA, 2008), os peixes reúnem características que os tornam excelentes modelos experimentais para estudos de biomonitoramento aquático (BENINCÁ, 2006; MORON et al., 2006; RAMISDORF, 2007). Os peixes, como os grandes vertebrados, têm sido considerados como ótimos organismos indicadores da qualidade da água (DAMATO, 1995; LOPES-POLEZA, 2004; PANTALEÃO, 2008) devido a sua capacidade de responder a elementos tóxicos (BENINCÁ, 2006). Além disso, os peixes desempenham funções diferentes na cadeia trófica e são capazes de bioacumular de forma direta contaminantes dissolvidos na água (LOPES- POLEZA, 2004; SOUZA e FONTANETTI, 2007).

Entre os peixes de água doce do Brasil, as tilápias (Figura 1) são espécies exóticas invasoras que têm sido usadas como organismos bioindicadores de poluição por apresentarem ampla distribuição geográfica e características ecológicas conhecidas (ARIAS et al., 2007; SOUZA e FONTANETTI, 2007). As tilápias são peixes ósseos, Actinopterygii: Perciformes, Cichlidae, de corpo alto e comprimido e apresentam escamas dérmicas implantadas, boca terminal e brânquias (NELSON, 2006).

Intensamente usada na piscicultura mundial, a tilápia está entre as espécies mais indicadas para o cultivo intensivo em regiões tropicais. Essa espécie apresenta qualidades interessantes para a produção píscícola como o curto ciclo de reprodução e rápido crescimento (RIBEIRO e CAETANO-FILHO, 1995). São também peixes muito utilizados em estudos que unem a genética toxicológica e os estudos de biomonitoramento ambiental (SOUZA e FONTANETTI, 2007).

Usando-se tilápias (Actinopiterygii: Cichlidae) comercializadas no Centro de Abastecimento de Feira de Santana como bioindicadores de poluição ambiental, o presente 
trabalho buscou contribuir para o conhecimento do impacto antrópico indesejável sobre os rios da Bacia do Paraguaçu, em Feira de Santana (Bahia).

Para julgar se há contaminação das tilápias foram realizados testes de micronúcleo celular como ferramenta de detecção. Os micronúcleos são estruturas visíveis no citoplasma de células interfásicas que apresentam características cromatínicas e coloração semelhante às do núcleo principal quando avaliados ao microscópio óptico (CARVALHO et al., 2002). São resultantes de fragmentos de cromossomos ou de cromossomos inteiros, que durante o processo de divisão celular falham em sua ligação ao fuso. Sua presença pode refletir a ocorrência de danos estruturais ao material genético e de aneuploidia (RODRIGUES e CASTILHOS, 2003; FREITA et al., 2005; PEREIRA et al., 2005; BUCKER et al., 2006; ARIAS et al., 2008). Os testes de micronúcleos celulares vêm sendo usados com frequência na análise e biomonitoramento de recursos hídricos, empregando peixes como indicadores ambientais para avaliar a qualidade de recursos hídricos e os efeitos da poluição sobre esses organismos (BUCKER et al., 2006; ARIAS et al., 2007; PANTALEÃO, 2008). Por dispensar cultura e ser rápido, o teste é considerado simples e barato (PEREIRA et al., 2005; GALIOTTE, 2008). CARVALHO et al. (2002) apontaram, como vantagens, a avaliação de grande número de amostras de maneira relativamente rápida e o fato de o método não ser invasivo, permitindo identificar aumento na frequência de mutação em células expostas à variada gama de agentes genotóxicos.

\section{FIGURA 1 - TILÁPIA COMPRADA NO CENTRO DE ABASTECIMENTO DE FEIRA DE SANTANA (BAHIA) - 2008}

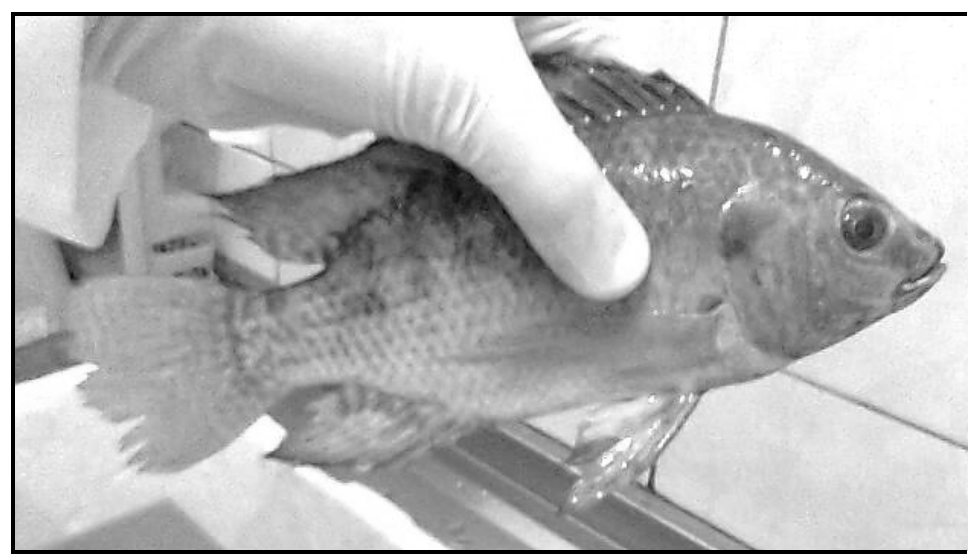

\section{MATERIAL E MÉTODOS}

No período de maio a agosto de 2008, vinte e dois espécimes de tilápias foram adquiridos no Centro de Abastecimento de Feira de Santana (CAFS) em sete coletas semanais. Os peixes ainda com vida foram transportados ao laboratório para as análises. Efetuaram-se as coletas de sangue necessárias para a confecção de lâminas para a análise dos micronúcleos presentes nos eritrócitos. As amostras foram retiradas por punção opercular, utilizando-se seringas hipodérmicas de 1 ou $3 \mathrm{~mL}$. Adotou-se essa técnica devido à dificuldade de extração de sangue da veia caudal como indicado na literatura (RODRIGUES et al., 2003; FERRARO et al., 2008). Efetuou-se o esfregaço do sangue coletado 
(RODRIGUES et al., 2003; BUCKER et al., 2006; PINHATTI et al. 2006), preparando diversas lâminas para cada peixe.

\subsection{PROTOCOLOS}

A partir da confecção do esfregaço foram obtidas 45 lâminas com boa qualidade para leitura, as quais seguiram três diferentes protocolos de preparo (Quadro 1).

O Protocolo 1 seguiu a metodologia proposta por PEREIRA et al. (2005), BENINCÁ (2006) e PINHATTI et al. (2006). Após a secagem do esfregaço à temperatura ambiente, a lâmina foi coberta com metanol a 100\% e aguardou-se o período de 15 minutos para fixação. Após, a lâmina recebeu a solução de corante Giemsa em pó diluído em solução tampão fosfato $(\mathrm{pH} \mathrm{6,8)}$ por 10 minutos.

No Protocolo 2, as lâminas foram confeccionadas conforme BUCKER et al. (2006). Após o esfregaço, aguardou-se o período de 24 horas para secagem do material antes da lâmina ser submetida aos 15 minutos de fixação com metanol 100\% e, posteriormente, a 20 minutos em Giemsa. Após a coloração, as duas lâminas dos diferentes protocolos foram lavadas com água destilada e secaram em temperatura ambiente.

Para o Protocolo 3, o metanol 100\% foi aplicado logo após a confecção do esfregaço, permanecendo por 15 minutos e somente 24 horas depois foi corado por 20 minutos.

\section{QUADRO 1 - NÚMERO DE PEIXES, NÚMERO DE LÂMINAS, TOTAL DE LÂMINAS ANALISADAS, PROTOCOLO UTILIZADO NAS LÂMINAS ESCOLHIDAS, QUANTIDADE TOTAL DE CÉLULAS EXAMINADAS, CONTAGEM DE MICRONÚCLEOS POR COLETA}

\begin{tabular}{|c|c|c|c|c|c|c|c|}
\hline Data da Coleta & $02 / 05 / 08$ & $19 / 05 / 08$ & $02 / 06 / 08$ & $07 / 07 / 08$ & $13 / 07 / 08$ & $21 / 07 / 08$ & $04 / 08 / 08$ \\
\hline No de Peixes & 3 & 6 & 3 & 4 & 3 & 2 & 1 \\
\hline $\begin{array}{c}\text { No de lâminas } \\
\text { por peixe }\end{array}$ & 1 & 1 & 2 & 3 & 3 & 3 & 3 \\
\hline $\begin{array}{c}\text { Total de } \\
\text { lâminas } \\
\text { analisadas }\end{array}$ & 3 & 6 & 1 & 4 & 3 & 2 & 1 \\
\hline $\begin{array}{c}\text { Protocolo } \\
\text { Utilizado nas } \\
\text { lâminas } \\
\text { escolhidas }\end{array}$ & 1 & 1 & 1 & 2,3 & 1 & 1 & 1 \\
\hline $\begin{array}{c}\text { Quantidade } \\
\text { total de } \\
\text { células } \\
\text { analisadas }\end{array}$ & 3000 & 6000 & 1000 & 4000 & 3000 & 2000 & 1000 \\
\hline $\begin{array}{c}\text { Quantidade } \\
\text { total de } \\
\text { Micronúcleos } \\
\text { encontrados }\end{array}$ & 22 & 30 & 7 & 21 & 18 & 20 & 2 \\
\hline
\end{tabular}

Dados colhidos a partir do sangue de tilápias comercializadas no Centro de Abastecimento de Feira de Santana (CAFS), Bahia -2008. 


\subsection{COLETA DO MATERIAL}

Para o protocolo 1 submeteram-se 9 lâminas, originárias dos peixes da primeira e segunda coletas. Essas ficaram muito escuras com a formação intensa de grânulos cristalizados, o que dificultou a visualização das células. Acredita-se que esse fato esteja relacionado com a pouca diluição do corante Giemsa. As lâminas foram encaminhadas para a etapa seguinte (Teste de Micronúcleo).

A terceira coleta de peixes originou 6 lâminas, sendo duas para cada peixe e diferentes metodologias (três lâminas conforme a metodologia do primeiro protocolo e três de acordo com o protocolo de BUCKER et al., 2006).

A partir da quarta coleta até a sétima, visando à obtenção de lâminas de melhor qualidade, nova solução de Giemsa foi adquirida. Além disso, outras modificações foram introduzidas: aumento do tempo de coloração de 10 para 20 minutos e a proteção das lâminas da luz.

\subsection{TESTE DE MICRONÚCLEO}

A análise citogenética foi realizada em microscópio óptico em resolução $1000 \mathrm{x}$ (BUCKER et al., 2006), utilizando-se lente objetiva de imersão (PEREIRA et al., 2005) para a contagem de micronúcleos presentes e posterior análise dos dados. Foram contadas 1.000 células por lâmina, bem como o número de ocorrência de micronúcleos (RODRIGUES et al., 2003; BUCKER et al., 2006; ARIAS et al., 2007).

O reconhecimento dos micronúcleos seguiu a metodologia adotada por CARVALHO et al. (2002) e FREITA et al. (2005), considerando-se como micronúcleos as estruturas com limites definidos, menores que o núcleo, com coloração semelhante e visualizadas no mesmo plano. A presença de micronúcleos foi interpretada como provável indício de danos genotóxicos ocasionados por poluentes e a consequente poluição dos rios dos quais os peixes são provenientes (LOPES-POLEZA, 2004; ARIAS et al., 2007).

\section{RESULTADOS E DISCUSSÃO}

As lâminas resultantes dos três protocolos apresentaram boa qualidade para visualização, sendo melhores as oriundas do protocolo 1 (não apresentaram coloração muito escura ou muitas células sobrepostas). Apenas na quarta coleta, as lâminas que seguiram o protocolo 2 e 3 ficaram mais visíveis. Isto se deve à má qualidade do esfregaço, o qual resultou em muitas células sobrepostas que dificultaram a visualização dos núcleos celulares no microscópio.

Das 45 lâminas produzidas, as melhores 20 lâminas de cada peixe foram escolhidas para serem analisadas (mais adequadas em termos de visualização ao microscópio).

Durante a confecção das lâminas, algumas estavam com a visualização comprometida por grânulos. A formação de grânulos nas lâminas foi atribuída aos cristais do corante Giemsa e por isso decidiu-se diluí-lo em solução tamponada e filtrá-lo em papel especial antes do uso. No entanto, o processo não resultou em lâminas melhores, pois as células ficaram muito claras e com núcleos não corados. Apenas 1 lâmina foi utilizada, sendo as demais descartadas. Nas vinte lâminas foram analisadas 20.000 células, sendo 1000 em cada lâmina e anotados todos os micronúcleos observados. Foram encontradas no total 110 células com micronúcleos (Figura 2) 


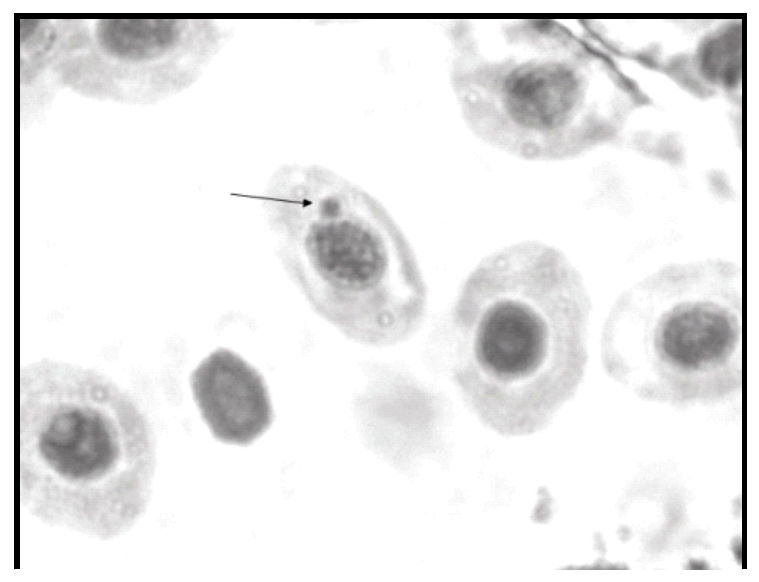

A seta indica a formação de micronúcleo.

A quantidade de micronúcleos observada quando comparada com a literatura evidenciou grande número desse tipo de alterações celulares. BENINCÁ (2006) realizou análises no Paraná em período chuvoso com o peixe Geophagus brasiliensis da mesma família que as tilápias (Cichlidae). Para o total de 84.000 células contadas de seu grupo controle positivo (contaminado com sulfato de cobre) foram encontrados 119 células alteradas. BENINCÁ (2006) e RAMSDORF (2007) observaram que os peixes coletados durante o inverno apresentam maiores danos e que o excesso de chuvas pode ocasionar carreamento de poluentes para os rios. Esses achados podem ser considerados como indício de danos genotóxicos nas tilápias vendidas no Centro de Abastecimento de Feira de Santana e consequentemente a poluição dos rios em que foram capturadas.

\section{CONCLUSÃO}

A partir da confecção de testes de micronúcleos extraídos de coletas sanguíneas de tilápias, há indícios de contaminação dos rios da Bacia do Paraguaçu que podem estar induzindo a formação dos micronúcleos.

Sendo a alimentação a maior rota de exposição humana a agentes tóxicos, esses peixes podem se tornar vetores de contaminação pela introdução de agentes genotóxicos na cadeia alimentar e gerar problema de Saúde Pública.

Estudos posteriores são recomendados a fim de se conhecer melhor a fonte de contaminação e a extensão do problema em todo o ecossistema aquático.

\section{ABSTRACT}

TILAPIAS (Actinopterygii:Cichlidae) COMMERCIALIZED AT FEIRA DE SANTANA, BAHIA (BRAZIL), AS ENVIRONMENT BIOINDICATORS OF POLLUTION IN PARAGUAÇU RIVERS BASIN

In the present study species of tilapia sold in the Centro de Abastecimento on the city of Feira de Santana (Bahia/Brazil) were used to assess the contamination of the rivers in the Paraguaçu basin. For that fish micronucleus test were carried out. Samples were collected at seven different times in the months of May to August 2008, and 22 specimens of tilapia were acquired. Three models of different protocols were used. In 
the first, the three steps were made on the same day, drying of the smear, fixing with methanol $100 \%$ and staining with Giemsa10\%. In the second, only the drying was held on the day of collection, the other steps were taken 24 hours later. In the third and last, only the staining was done in subsequent days. In a total of 20,000 cells, 119 micronuclei were found, which indicates the action of genotoxic agents in the cells of the fish. Their consumption in large-scale may establish genotoxic agents contamination chains of the population of Feira de Santana. Additional studies are suggested to identify the agent and contamination chain therefore to implement the required measures for the restoration of health and the quality of life

KEY-WORDS: BACIA OF PARAGUAÇU; BIOINDICATORS; TILÁPIAS; MICRONUCLEI.

\section{REFERÊNCIAS}

1 ARIAS, A.R.L. et al. Use of bioindicators for assessing and monitoring pesticides contamination in streams and rivers. Ciênc. Saúde Coletiva, Rio de Janeiro, v. 12, n. 1. 2007. Disponível em: http:// www.scielo.br/scielo.php?script=sci_arttext\&pid=S141381232007000100011\&lng=en\&nrm=iso $>$. Acesso em: 30 jun. 2008.

2 ARIAS, A.R.L. et al. Utilização de bioindicadores como ferramentas de monitoramento e avaliação ambiental: o caso de recursos hídricos. Centro de Estudos da Saúde do Trabalhador e Ecologia Humana - CESTEH \& Fundação Oswaldo Cruz - FIOCRUZ. Rio de Janeiro. 2008. Disponível em: $<w w w$. fiocruz.br/cesteh >. Acesso em: 30 jun. 2008.

3 BAHIA. Secretaria do Planejamento, Ciência e Tecnologia. Recursos hídricos do Estado da Bahia: ênfase ao Semi-Árido. Salvador: CAR, 1995. p 57.

4 BAHIA. Centro de Recursos Ambientais da Bahia. Bacia do Rio Paraguaçu. Salvador: CRA, 2001. p.102-105.

5 BENINCÁ, C. Biomonitoramento das lagoas estuarinas do Camacho - Jaguaruna (SC) e Santa MartaLaguna (SC), utilizando Geophagus brasiliensis (CICHLIDAE). 112 f. Dissertação (Mestrado em Genética), Departamento de Genética, Universidade Federal do Paraná, Curitiba, 2006.

6 BUCKER, A. et al. Avaliação da mutagênese e genotoxicidade em Eigenmannia virescens (Teleostei: Gymnotiformes) expostos ao benzeno. Acta Amazonica, Manaus, v. 36, n. 3, p. 357-364, 2006.

7 CARVALHO, M. B. et al. Correlação entre a evolução clínica e a frequência de micronúcleos em células de pacientes portadores de carcinomas orais e da orofaringe. Rev. Assoc. Med. Bras., São Paulo, v. 48, n. 4, p. 317- 322, 2002.

8 DAMATO, M. Determinação da toxicidade aguda de dicromato de potássio para Phalloceros caudimaculatus, Poecilia vivipara e Cyprinus carpio. In: ENCONTRO BRASILEIRO DE ICTIOLOGIA, 11. Campinas, 1995. Resumos ... Campinas: Pontifícia Universidade Católica de Campinas/Sociedade Brasileira de Ictiologia, 1995.

9 FERRARO, M. V. M. et al. Mutagenic effects of tributyltin and inorganic lead ( $\mathrm{Pb}$ II) on the fish $\mathrm{H}$. malabaricus as evaluated using the comet assay and the piscine micronucleus and chromosome aberration tests. Genet. Mol. Biol., São Paulo, v. 27, n.1, 2004. Disponível em: http://www.scielo.br/ scielo.php?script= sciarttext\&pid=S14 547572004000100017\&lng=en\&nrm=iso. Acesso em: 8 abr. 2008.

10 FREITA, V. S. et. al. Efeitos genotóxicos de fatores considerados de risco para o câncer bucal. Revista Baiana de Saúde Pública, v. 29, n. 2, p. 189 -199, jul./dez.2005.

11 GALIOTTE, M. DNA de profissional de beleza sofre mais alterações. Canal Executivo Uol: Artigos. Disponível em: <http://www2.uol.com.br/canalexecutivo/ notas06/220920063.htm>. Acesso em: 21 jun. 2008.

12 LOPES-POLEZA, S. D. C. Avaliação do efeito do metilmercúrio (CHHG+) em Hoplias malabaricus através da frequência de aberrações cromossômicas e dos ensaios Cometa e Micronúcleo. 70 f. Dissertação (Mestrado em Genética), Universidade Federal do Paraná. Curitiba, 2004.

13 MEDINA, B. M. O. Indicadores ambientais. Ecologia hoje. Disponível em: <http://www.biologo.com.br/ ecologia/ecologia3.htm>. Acesso em: 3 jul. 2008. 
14 MEGER, D. G.; TREVISAN, E. Importância dos componentes bióticos como indicadores ambientais nas Bacias Hidrográficas do estado. Paraná. Comitê de Bacia Hidrográfica do Rio Jordão (Médio Iguaçu). Governo do Paraná. SUDERHSA - Superintendência de Desenvolvimento dos Recursos Hídricos e Saneamento do Paraná. 2007. Disponível em: < www.suderhsa.pr.br > Acesso em: 21 jun. 2008.

15 MORON, S. E. et al. Estudo de alterações na concentração de íons plasmáticos e da indução de micronúcleos em Piaractus mesopotamicus exposto ao herbicida Atrazina. J. Braz. Soc. Ecotoxicol.,

v. 1, n. 1, p. 27-30, 2006.

16 NELSON, J. S. Fishes of the world. $4^{\text {th }}$ ed. New York: Wiley \& Sons, 2006.

17 PANTALEÃO, S. M. Impacto genotóxico de poluentes químicos presentes na água e sedimento do Rio Japaratuba (Sergipe). Disponível em: < http://biblioteca.universia.net/ficha.do?id=5582691> Acesso em: 3 jul. 2008.

18 PEREIRA, G. B. et al. Detecção de micronúcleo em Melipona scutellaris LATREILLE (Hymenoptera, Apidae, Meliponini) In: ENCONTRO INTERNO DE INICIAÇÃO CIENTÍFICA, 5., e SEMINÁRIO DE INICIAÇÃO CIENTÍFICA, 9., Uberlândia, 2005. Anais... Uberlândia: Universidade Federal de Uberlândia, 2005.

19 PINHATTI, V.R. et al. Determinação de danos basais no DNA de araras canindé (Ara ararauna) através do teste de micronúcleos: uma ferramenta na avaliação da saúde animal e seu uso no biomonitoramento da poluição ambiental. Acta Scientiae Veterinariae, v. 3, n. 34, p. 313-317, 2006.

20 RAMSDORF,W. Utilização de duas espécies de Astyanax (Astyanax sp B e A. altiparana) como bioindicadores de região contaminada por agrotóxico (Fazenda Cangüiri- UFPR). 127 f. Dissertação (Mestrado em Genética), Departamento de Genética, Universidade Federeal do Paraná, Curitiba, 2007.

21 RIBEIRO, S. C.; CAETANO-FILHO, M. Comparação morfométrica de duas populações de Hoplias malabaricus (CHARACIFORMES - ERYTHRINIDAE) da Bacia do Rio Tibagi, PR). In: ENCONTRO BRASILEIRO DE ICTIOLOGIA, 11., Campinas, 1995. Resumos... Campinas: Pontifícia Universidade Católica de Campinas/Sociedade Brasileira de Ictiologia, 1995.

22 RODRIGUES, A. P. C.; CASTILHOS, Z. C. Avaliação de risco ecológico em ecossistemas aquáticos contaminados por mercúrio. Estudo de caso: Ilha das Enxadas, Baía de Guanabara, RJ. In: JORNADA DE INICIAÇÃO CIENTÍFICA - CETEM, 11., Rio de Janeiro, 2003. Anais... Rio de Janeiro: CETEM, 2003.

23 SOARES, J. F. Brasil: riqueza em água e em leis de recursos hídricos. In: Eco 21. Rio de Janeiro: Eco 21. Ano XIV Agosto n. 93. 2004. Disponível em: <www.eco21.com.br>. Acesso em: 21 jun. 2008.

24 SOUZA, T. S.; FONTANETTI, C. S. Ensaio do cometa para avaliação da qualidade das águas do Rio Paraíba do Sul, numa área sob influência de uma refinaria de petróleo. In: CONGRESSO BRASILEIRO DE PESQUISA E DESENVOLVIMENTO EM PETRÓLEO E GÁS, 4., Campinas, 2007. Anais... Campinas: PDPETRO, 2007.

\section{AGRADECIMENTOS}

Os autores agradecem à Professora Renata Canalle (Instituto de Ciências Ambientais e Desenvolvimento Sustentável da Universidade Federal do Piauí - UFPI), à Professora Dra. Eneida de Moraes Marcílio Cerqueira, ao Laboratório de Microbiologia Aplicada, Ambiental e Saúde Pública (LAMASP), ao Centro de Referência de Informação em Saúde (CRIS) e ao Laboratório Didático do Departamento de Ciências Biológicas da Universidade Estadual de Feira de Santana por todo apoio, materiais e informações cedidas para a confecção deste trabalho de pesquisa. 